\title{
Analisando as percepções de professores sobre o racismo na educação
}

Eduarda Soares de Almeida* Victor Hugo Nedel Oliveira**

\begin{abstract}
Resumo:
O racismo é um assunto muito importante e delicado de se tratar em sala de aula. Esta é uma pesquisa que teve como objetivo principal de analisar o que os professores do 70 ano do Ensino Fundamental do Colégio de Aplicação da UFRGS pensam sobre o racismo. Para atingir os objetivos propostos foi realizada a leitura de materiais selecionados e a aplicação de um questionário. Os resultados obtidos com a pesquisa evidenciaram que a maioria dos professores participantes era do gênero feminino, da etnia branca e residente em Porto Alegre. A totalidade dos sujeitos concorda plenamente com a afirmação de que "negros sofrem racismo todo o dia no Brasil". A absoluta maioria dos sujeitos concorda com as afirmações "todos os negros sofrem racismo" e "os negros são o principal alvo de racismo no Brasil". É possível considerar, portanto, que o racismo em suas múltiplas faces é notadamente percebido pelos professores que participaram da investigação.
\end{abstract}

\section{Palavras-chaves:}

Preconceito. Racismo. Educação. Escola. Professores.

\section{Resumen:}

El racismo es un tema muy importante y delicado para tratar en el aula. Esta es una investigación que tuvo como objetivo principal analizar lo que los maestros de 70 año de la escuela primaria de la Facultad de Aplicación de UFRGS piensan sobre el racismo. Para lograr los objetivos propuestos, se llevó a cabo la lectura de materiales seleccionados y la aplicación de una encusta. Los resultados obtenidos con la investigación mostraron que la mayoría de los profesores participantes eran mujeres, blancos y residentes en Porto Alegre. Todos los sujetos están totalmente de acuerdo con la afirmación de que "los negros sufren racismo todo el día en Brasil". La mayoría absoluta de los sujetos está de acuerdo con las afirmaciones "todos los negros sufren el racismo" y "los negros son el principal objetivo del racismo en Brasil". Se puede considerar, por tanto, que el racismo en sus múltiples caras es percibido notablemente por los docentes que participaron del investigación.

\section{Palabras-clave:}

Prejuicio. Racismo. Educación. Escuela. Profesores.

\footnotetext{
* Estudante do 9o ano do Ensino Fundamental do Colégio de Aplicação da Universidade Federal do Rio Grande do Sul. E-mail: eduardasoares06620@gmail.com.

** Doutor em Educação, professor do Departamento de Humanidades da Universidade Federal do Rio Grande do Sul. E-mail: victor.juventudes@gmail.com. ORCID iD: http://orcid.org/0000-0001-5624-8476.
} 


\section{Introdução}

O assunto dessa pesquisa é sobre preconceito/racismo, e, como recorte, escolheu-se o tema racismo e educação na visão dos professores. A pergunta de pesquisa desta investigação foi: "O que os professores do Amora 2 têm realizado para a construção de uma sociedade não racista?” e as perguntas secundárias foram: "O que é racismo?"; "Mudou alguma coisa de alguns anos para cá, sobre o que está sendo feito nas escolas sobre o racismo?"; “Como está evoluindo a educação antirracista?"; "Nos outros países, o que é feito?”.

Esta pesquisa foi resultante do Projeto Pixel'1 do Colégio de Aplicação da UFRGS e, no oitavo ano, o tema central das investigações é "identidade", portanto, esta pesquisa relaciona-se com o tema, pois cada vez mais as escolas estão ensinando a igualdade, que todos temos direitos, independentemente da cor, gênero ou classe social.

A justificativa desta investigação é que se acredita ser muito importante tratar de um assunto que está tão presente na nossa sociedade brasileira, e, também, ver o que os professores estão fazendo para evitar o racismo nas salas de aulas.

O que se sabia, antes de realizar a investigação sobre o tema escolhido, era: o racismo está muito presente na nossa sociedade brasileira. Existe uma lei (10.639/03) que torna obrigatório o ensino da história e cultura afro-brasileira.

Os objetivos desta investigação foram: analisar o que os professores do Amora 2 pensam sobre racismo e o que eles fazem quando têm um assunto de preconceito na sua sala de aula.

\section{Revisão bibliográfica}

Para explorar o tema que se escolheu para a pesquisa, realizaram-se dois movimentos: a leitura de livros selecionados na biblioteca do Colégio de Aplicação e a leitura de artigos científicos selecionados a partir de levantamento no Google Acadêmico.

\section{Biblioteca}

O primeiro livro intitulava-se Enciclopédia Mirador Internacional (ENCICLOPÉDIA..., 1995). Os principais aprendizados com este material foram: a discriminação aparece na época moderna na sociedade européia, dentro da conjuntura socioeconômica; o conceito de raça, com suas múltiplas significados, trabalhado como um instrumento capaz de gerar estados de "guerra" ou dominação política, deve ser visto como mito moderno; as raças são unidades biológicas mais populares e sensíveis às mudanças evolutivas.

O segundo livro intitulava-se Dicionário de Sociologia, de Johnson (1997). Os principais aprendizados com este material foram: preconceito é a teoria da desigualdade racial, entre outras formas, e discriminação é sua prática; o racismo que brancos dirigem a negros e outras pessoas de cor, inclui crenças estereotipadas sobre diferenças raciais em áreas como inteligência, motivação, caráter moral e habilidades diversas; qualquer preconceito com base racial constitui racismo assim como qualquer preconceito, por exemplo: no sexismo, etnia entre outros.

O terceiro livro intitulava-se O que é Racismo, escrito por Santos (1941). Os principais aprendizados com este material foram: o racismo é basicamente uma agressão contra outros; a pessoa que foi discriminada tem o direito de revidar; o racismo entre tanto, não é só uma atitude, o racismo também é uma teoria, defendida em livros e salas de aulas com argumento e teses "científicas"; nos EUA foram apresentadas "provas” das diferenças genéticas entre as raças negras e brancas.

1. Disponível em: http://www.ufrgs.br/projetopixel. 
O quarto livro intitulava-se Nova Enciclopédia (NOVA..., 1996). Os principais aprendizados com este material foram: a ideia de que as faculdades humanas são determinadas pela raça ou grupo étnico.

\section{Artigos científicos}

O primeiro artigo científico intitulava-se "Formação dos professores, educação infantil e diversidade étnico-racial; saberes e fazeres nesse processo" (DIAS, 2012). Os principais aprendizados com este texto foram que uma das principais conclusões da pesquisa está no dizer das professoras, que afirmam perceber a discriminação no seu cotidiano escolar, mas precisam de oportunidades institucionais nas quais possam discutir e estudar o tema.

O segundo artigo científico intitulava-se "Educação, identidade negra e formação de professores: um olhar sobre o corpo negro e cabelo crespo" (GOMES, 2003). Os principais aprendizados com este texto foram: o estudo sobre as representações do corpo negro no cotidiano escolar poderá ser uma contribuição não só para o desvelamento do preconceito e da discriminação racial na escola como, também, poderá nos ajudar a construir estratégias pedagógicas alternativas que nos possibilitem compreender a importância do corpo na construção da identidade étnico-racial de alunos, professores negros, mestiços e brancos e como esses fatores interferem nas relações estabelecidas entre esses diferentes sujeitos no ambiente escolar. $\mathrm{Na}$ escola, não só aprendemos, mas também reproduzimos representações sobre o cabelo crespo e o corpo negro. Quais serão essas representações? Em que momentos aparecem e como elas aparecem? Como os sujeitos negros e brancos vivem esses processos dentro e fora da escola? Como tais representações se manifestam no currículo? Muitas vezes, esses processos delicados e tensos passam despercebidos pela escola, pelos profissionais da educação, e não constituem motivo de debates e estudos nos nossos cursos de formação de professores. O estudo sobre o corpo e o cabelo como ícones da identidade negra presentes nos processos educativos escolares e não-escolares poderá nos apontar outros caminhos além da denúncia da reprodução de preconceitos e estereótipos. Ver a manipulação do cabelo do negro e da negra como continuidade de elementos culturais africanos ressignificados no Brasil poderá nos pôr em contato com a história, memória e herança cultural africana presente na formação cultural afro-brasileira. O terceiro artigo científico intitulava-se "Ação afirmativa, relações raciais e educação básica" (VALENTE, 2005).

\section{Aprendizados com as referências}

As principais questões aprendidas com esses autores e utilizadas na pesquisa foram que a cultura negra, e afro-brasileira está muito presente na nossa sociedade escolar e os professores estão querendo cada vez mais colocar dentro da escola o assunto. E cada vez mais os negros estão presentes na nossa sociedade brasileira. 


\section{Metodologia}

O roteiro básico da pesquisa foi organizado da seguinte forma: primeiro, a caracterização da amostra; logo, verificar o grau de concordância dos entrevistados; e, por fim, comparar as respostas com o colega. O tipo de pesquisa que escolheu-se realizar foi qualitativa, porque vai ver a opinião dos entrevistado sendo feito um levantamento no final. O universo da investigação foram os Professores do Amora 2 ( $7^{\circ}$ ano do Ensino Fundamental) e a amostra (recorte) foram 16 professores da turma do Amora 2.

Para a coleta de dados, o instrumento de coleta de dados será o questionário. O questionário foi elaborado da seguinte forma: caracterização da amostra (gênero, idade e etnia); afirmações e grau de concordância. Para analisar as informações coletadas, realizou-se montagem de gráficos com o grau de concordâncias dos professores.

\section{Resultados}

Os resultados da pesquisa foram divididos em duas etapas, a primeira apresentando a caracterização da amostra da pesquisa e a segunda parte apresentando e discutindo os dados coletados na investigação, a partir da interpretação da escala Likert.

\section{Amostra de pesquisa}

Idade

\section{Gráfico 1 - Gráfico sobre idade}

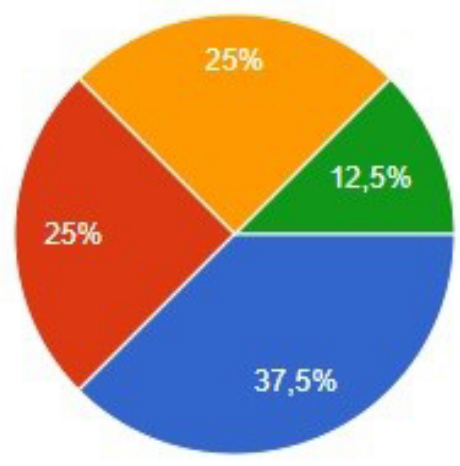

18 a 30 anos

31 e 40 anos

41 e 50 anos

50 anos ou mais

Fonte: Elaborado pelos autores (2019).

Da amostra de pesquisa pode-se constatar que 37,5\% estão na faixa dos 8 aos 30 anos; 25\% estão na faixa dos 31 aos 40 anos, 25\% possuem 41 aos 50 anos e 12,5\% estão na faixa de 50 anos ou mais. Ou seja, a maioria da amostra de pesquisa encontra-se na faixa dos 18 aos 30 anos. 


\section{Gênero}

\section{Gráfico 2 - Gráfico sobre gênero}

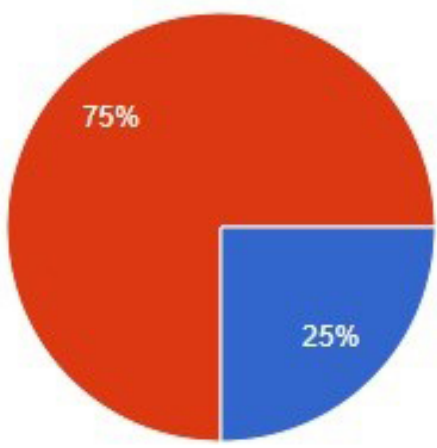

Masculino

Feminino

Prefiro não dizer

Fonte: Elaborado pelos autores (2019)

Da amostra de pesquisa pode-se constatar que $25 \%$ são do gênero masculino, $75 \%$ são do sexo feminino e $0 \%$ preferiram não responder sobre a questão de gênero. Ou seja, a maioria da amostra de pesquisa identifica-se com o gênero feminino.

Etnia

Gráfico 3 - Gráfico sobre etnia

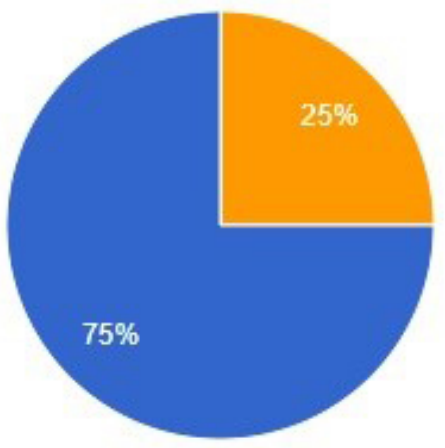

indigena

Fonte: Elaborado pelos autores (2019)

Da amostra de pesquisa pode-se constatar que $75 \%$ identificam-se como brancos, $0 \%$ identifica-se como negros, $25 \%$ identificam-se como pardos, $0 \%$ identifica-se como indígenas e $0 \%$ afirmou identificar-se com outras etnias. Ou seja, a maioria da amostra de pesquisa identifica-se com a etnia branca. 


\section{Onde mora}

\section{Gráfico 4 - Gráfico sobre local de residência}

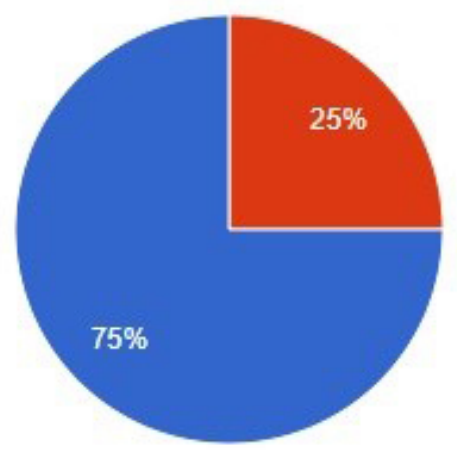

Porto Alegre

outros municípios

Fonte: Elaborado pelos autores (2019).

Da amostra de pesquisa pode-se constatar que 75\% moram em Porto Alegre e $25 \%$ moram em outras cidades. Ou seja, a maioria da amostra de pesquisa mora em Porto Alegre.

\section{Escala Likert}

\section{Afirmação 1: "Negros sofrem todos os dias racismo no Brasil"}

A afirmação 1 era: "Negros sofrem todos os dias racismo no Brasil”. Escolheu-se essa afirmação, pois pensamos na sociedade negra em geral.

\section{Gráfico 5 - Gráfico com afirmação 1 da Escala Likert}

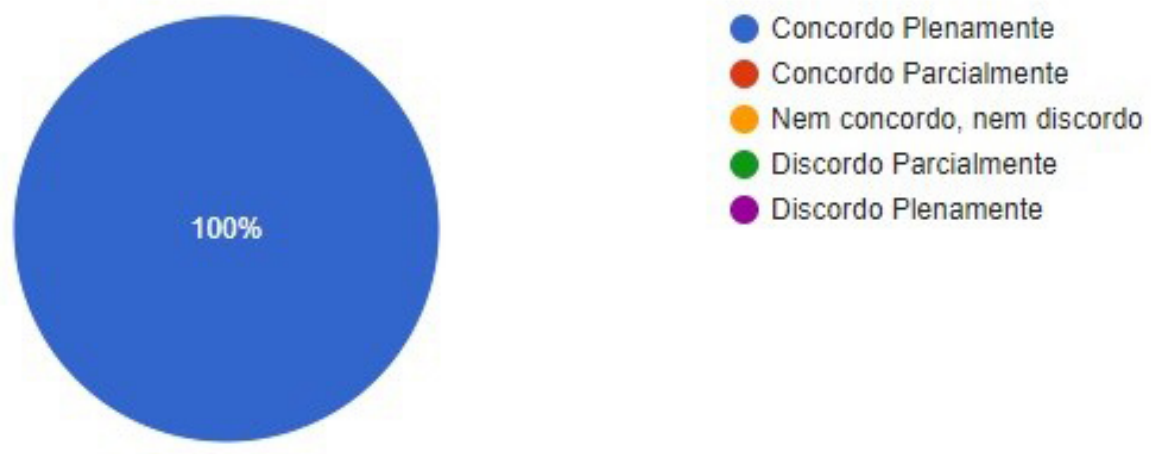

Fonte: Elaborado pelos autores (2019).

Pode-se constatar que $100 \%$ concordam plenamente com a afirmação; $0 \%$ concorda parcialmente; $0 \%$ nem concordam nem discordam; $0 \%$ discorda parcialmente e que $0 \%$ discorda totalmente da afirmação. 


\section{Afirmação 2: "Todos os negros sofrem racismo"}

A afirmação 2 era: "Todos os negros sofrem racismo". Escolheu-se essa afirmação, pois quando toca no assunto racismo, o principal alvo que sofre preconceito são os negros.

\section{Gráfico 6 - Gráfico com afirmação 2 da Escala Likert}

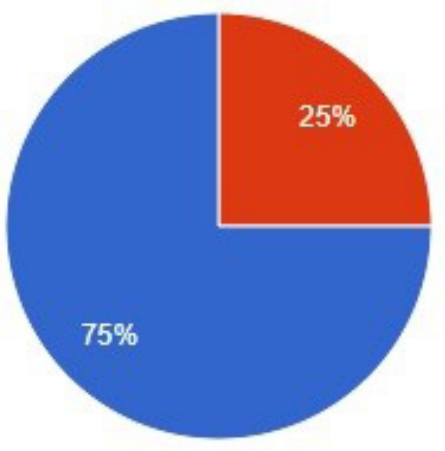

Concordo Plenamente

Concordo Parcialmente

Nem concordo, nem discordo

Discordo Parcialmente

Discordo Plenamente

Fonte: Elaborado pelos autores (2019).

Pode-se constatar que $75 \%$ concordam plenamente com a afirmação; $25 \%$ concordam parcialmente; $0 \%$ nem concordam nem discordam; $0 \%$ discordam parcialmente e que $0 \%$ discordam totalmente da afirmação.

\section{Afirmação 3: "O principal alvo do racismo são os negros"}

A afirmação 3 era: "O principal alvo do racismo são os negros". Escolheu-se essa afirmação, pois é um fato presente na sociedade brasileira.

Gráfico 7 - Gráfico com afirmação 3 da Escala Likert

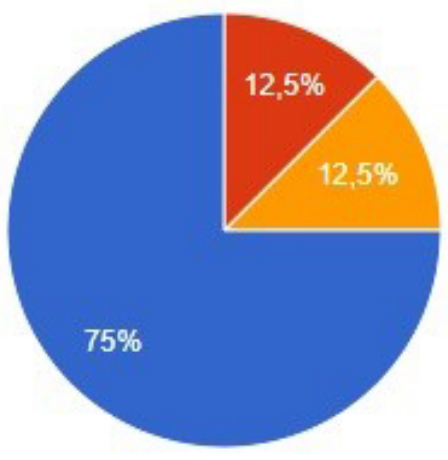

Concordo Plenamente

Concordo Parcialmente

Nem concordo, nem discordo

Discordo Parcialmente

Discordo Plenamente

Fonte: Elaborado pelos autores (2019).

Pode-se constatar que $75 \%$ concordam plenamente com a afirmação; $12,5 \%$ concordam parcialmente; $12,5 \%$ nem concordam nem discordam; $0 \%$ discorda parcialmente e que $0 \%$ discorda totalmente da afirmação. 


\section{Afirmação 4: "Negros são considerados a minoria na nossa sociedade"}

A afirmação 4 era: "Negros são considerados a minoria na nossa sociedade". Escolheu-se essa afirmação, pois não temos costumes de ver professores negros dando aula.

\section{Gráfico 8 - Gráfico com afirmação 4 da Escala Likert}

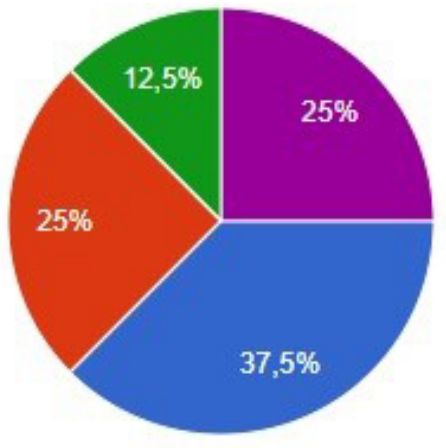

Concordo Plenamente

Concordo Parcialmente

Nem concordo, nem discordo

Discordo Parcialmente

Discordo Plenamente

Fonte: Elaborado pelos autores (2019).

Pode-se constatar que 37,5\% concordam plenamente com a afirmação; $25 \%$ concordam parcialmente; $0 \%$ nem concordam nem discordam; $12,5 \%$ discordam parcialmente e que $25 \%$ discordam totalmente da afirmação.

\section{Afirmação 5: "Brancos praticam racismo com negros"}

A afirmação 5 era: "Brancos praticam racismo com negros". Escolheu-se essa afirmação, pois geralmente quando vemos alguma notícia de racismo na televisão ou em um jornal, o agressor é o branco.

\section{Gráfico 9 - Gráfico com afirmação 5 da Escala Likert}

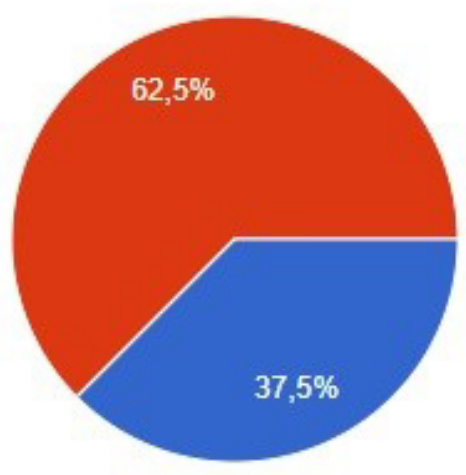

Concordo Plenamente

Concordo Parcialmente

Nem concordo, nem discordo

Discordo Parcialmente

Discordo Plenamente

Fonte: Elaborado pelos autores (2019).

Pode-se constatar que 37,5\% concordam plenamente com a afirmação; $62,5 \%$ concordam parcialmente; $0 \%$ nem concordam nem discordam; $0 \%$ discorda parcialmente e que $0 \%$ discorda totalmente da afirmação. 


\section{Afirmação 6: "Negros praticam racismo com brancos"}

a afirmação 6 era: "Negros praticam racismo com brancos". Escolheu-se essa afirmação, pois queria-se comparar com a afirmação anterior.

\section{Gráfico 10 - Gráfico com afirmação 6 da Escala Likert}

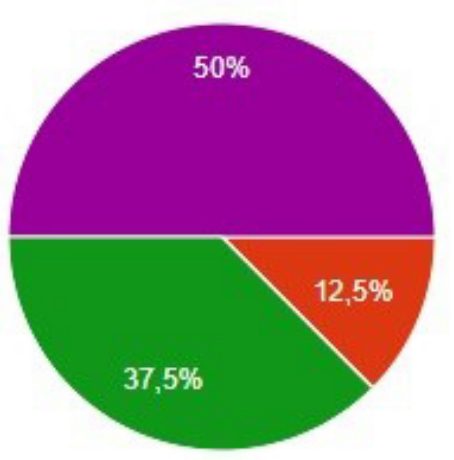

Concordo Plenamente

Concordo Parcialmente

Nem concordo, nem discordo

Discordo Parcialmente

Discordo Plenamente

Fonte: Elaborado pelos autores (2019).

Pode-se constatar que $0 \%$ concorda plenamente com a afirmação; $12,5 \%$ concordam parcialmente; $0 \%$ nem concordam nem discordam; $37,5 \%$ discordam parcialmente e que $50 \%$ discordam totalmente da afirmação.

\section{Ações antirracistas promovidas pelos professores}

Ao questionário dos professores sobre quais ações antirracistas eles proporcionam em aula, as respostas foram:

$\mathrm{S1}^{2}$ : Procuro tratar os estudantes com respeito a partir das regras que valem para todos, além de oferecer as mesmas oportunidades de aprendizagem nas turmas com as quais trabalho.

S2: Debates quando a questão surge espontaneamente.

S3: Projetos literários com leitura de livros que abordam essas questões, debates sobre racismo, estereótipos. Discussão sobre tons de pele e o que isso significa para a sociedade. Pesquisas de personalidades negras e sua importância.

S4: Sempre incluo personalidades negras de diferentes países nas atividades que planejo. Tento resgatar com os alunos a importância do legado dessas personalidades para a sociedade.

S5: Indiretamente, tento discutir questões termos como "empatia", além de tentar mostrar como o Brasil teve uma história forjada em cima do racismo, de modo que os alunos tentem compreender a importância de falarmos sobre esse tema.

S6: Desenvolvimento da noção de interculturalidade e alteridades, para que possamos ver no diferente e no diverso uma riqueza, uma oportunidade de crescimento como pessoas e humanidade.

S7: Valorização das produções científicas e dos saberes de afrodescendentes e de diferentes etnias; intolerância a atitudes racistas; atividades integradas entre os meus estudantes e estudantes de outras etnias.

2. A fim de manter o anonimato dos sujeitos da pesquisa, as respostas dos mesmos foram identificadas pela letra $S$ (significando "sujeito") e o número subsequente. Assim, "S1" significa "Sujeito 1", e assim por diante. 
S8: Acredito que ações antirracistas precisam acontecer em todas as aulas. Toda ação preconceituosa e desrespeitosa realizada em aula precisa ser problematizada para que se transforme em uma ação de conscientização. Além disso, os professores devem incluir, em seus planejamentos, momentos que promovam a reflexão sobre problemas sociais como o racismo. Um exemplo de ação antirracista promovido por mim e por meus colegas é um projeto, desenvolvido para o ensino de leitura e escrita, que tem o racismo como temática. Para tanto, foram escolhidos diferentes textos que abordam a problemática. Uma das propostas foi, inclusive, propor que os estudantes buscassem maneiras de intervir e tentar resolver situações de racismo trazidas nas obras literárias, proporcionando a possibilidade de os alunos, negros ou não, se colocarem no lugar do outro para refletir sobre atitudes antirracistas que podem praticar no seu cotidiano.

Os tópicos que ficaram em comum nas respostas dos professores foram que todos falam de racismo em sua aula, ou tentam trazer atividades que possam falar sobre o racismo, por exemplo, um projeto de leitura e escritura que tem o racismo como temática.

As questões que mais chamaram atenção foram que todos os professores colocam o tema de racismo em suas aulas.

A partir do exposto pelos professores, acredita-se que o ideal é fazer é colocar mais professores negros dando aula, e também, mais palestras que envolvem o conceito de racismo, como identificar que você está sofrendo racismo e com quem você pode relatar essas "agressões".

\section{Considerações finais}

Assim como o projeto de pesquisa e a realização das etapas metodológicas são muito importantes, a chegada nas conclusões da pesquisa também é. Assim, apresentam-se as considerações da pesquisa:

\section{Quanto às pesquisas bibliográficas (biblioteca e artigos no google acadêmico)}

Muitos livros de alguns anos atrás falavam muito sobre o conceito de raça, qual o seu significado e o que são. Em outros, o conceito de raça era visto como mito moderno. Já nas revistas científicas, a maioria falava sobre o cabelo crespo/cacheado e o preconceito que enfrentaram quando eram crianças por serem negras e tiver cabelo cacheado. Muitas das entrevistadas (que são cabeleireiras) relataram que sofreram, sim, muito preconceito por ter cabelo crespo ou cacheado na sua infância.

\section{Quanto à aplicação do instrumento de pesquisa}

No questionário pude constar que os entrevistados têm muitas respostas diferentes, no entanto, o grau de concordância das pessoas foi muito variado, por exemplo, na afirmação 4 "Negros são considerados a minoria na nossa sociedade" pude constar que $37,5 \%$ concordam plenamente com a afirmação; $25 \%$ concordam parcialmente; $0 \%$ nem concordam nem discordam; $12,5 \%$ discordam parcialmente e que $25 \%$ discordam totalmente da afirmação, ficando a "resposta" muito variada.

\section{Aprendizados para além da investigação}

Os principais aprendizados com essa pesquisa foram: na pesquisa conseguiu-se ver que a sociedade negra construiu um papel muito grande na nossa sociedade brasileira, mas que ainda tem muito a evoluir, pois nem todos os negros têm votos ou não sofrem preconceito a cada dia a dia. 
Os principais aprendizados, para além dos resultados, ou seja, o que se aprendeu para a vida nesta pesquisa foi: que a cultura negra é uma coisa muito importante para nós brasileiros, e que os negros também contam muito da nossa história afro-brasileira.

Além disso, foi possível aprender que fazer pesquisa científica no colégio é importante, pois você tem chances de expandir o seu aprendizado e saber coisas novas sobre um assunto no qual você possa ter dúvida.

\section{Referências}

DIAS, Lucimar Rosa. Formação de professores, educação infantil e diversidade étnico-racial: saberes e fazeres nesse processo. Revista Brasileira de Educação, Rio de Janeiro, v. 17, n. 51, p. 661-749, set./dez. 2012. Disponível em: https://www.scielo.br/pdf/rbedu/v17n51/10.pdf. Acesso em: 14 set. 2020.

ENCICLOPÉDIA Mirador Internacional: enciclopédia. 2. ed. São Paulo: Enciclopédia Britannica do Brasil, 1995. 9536 p. v. 2.

GOMES, Nilma Lino. Educação, identidade negra e formação de professores/as: um olhar sobre o corpo negro e o cabelo crespo. Educação e Pesquisa, São Paulo, v. 29, n. 1, p. 167-182, jan./jun. 2003. Disponível em: https://www.scielo.br/ pdf/ep/v29n1/a12v29n1.pdf. Acesso em: 14 set. 2020.

JOHNSON, Allan. Dicionário de Sociologia. Rio de Janeiro: Zahar, 1997.

NOVA Enciclopédia Ilustrada Folha: enciclopédia. 2. ed. São Paulo: Folha de São Paulo, 1996. 815 p. v. 2.

SANTOS, Joel Rufino. O que é Racismo. Brasília: Editora Brasiliense, 1941.

VALENTE, Lucia Ana. Ação afirmativa, relações raciais e educação básica. Revista Brasileira de Educação, Rio de Janeiro, v. 1, n. 28, p. 62-77, jan./abr. 2005. Disponível em: https://www.scielo.br/pdf/rbedu/n28/a06n28.pdf. Acesso em: 14 set. 2020.

Data de submissão: 15/07/2020

Data de aceite: 15/09/2020 